\title{
Effects of New Anti-Adhesion Polyvinyl Alcohol Gel on Healing of Colon Anastomoses in Rats
}

\author{
Juliette C. Slieker, Max Ditzel,, Joris J. Harlaar,, Irene M. Mulder, Eva B. Deerenberg,, \\ Yvonne M. Bastiaansen-Jenniskens, ${ }^{3}$ Gert-Jan J. Kleinrensink, ${ }^{2}$ Johannes Jeekel, ${ }^{2}$ and Johan F. Lange ${ }^{1}$
}

\begin{abstract}
Background: Adhesions follow abdominal surgery with an incidence as high as $95 \%$, resulting in invalidating complications such as bowel obstruction, female infertility, and chronic pain. Searches have been performed for a safe and effective adhesion barrier; however, such barriers have impaired anastomotic site healing. The primary aim of this study was to investigate the effect of a new adhesion barrier, polyvinyl alcohol gel, on healing of colonic anastomoses using a rat model.

Methods: Thirty-two Wistar rats were divided in two groups. In all animals, an anastomosis was constructed in the ascending colon. The first group received no adhesion barrier, whereas in the second group, $2 \mathrm{~mL}$ of polyvinyl alcohol gel (A-Part Gel ${ }^{\circledR}$; Aesculap AG, Tuttlingen, Germany) was applied circularly around the anastomosis. All animals were sacrificed on the seventh post-operative day, and the abdomen was inspected for signs of anastomotic leakage. The anastomotic bursting pressure, the adhesions around the anastomosis, and the collagen content of the excised anastomosis were measured.

Results: No significant differences were observed between the two groups in the incidence of anastomotic leakage, the anastomotic bursting pressure $(p=0.08)$, or the collagen concentration $(p=0.91)$. No significant reduction in amount of adhesions was observed in the rats receiving polyvinyl alcohol gel.

Conclusions: This experimental study showed no significant differences in anastomotic leakage, anastomotic bursting pressure, or collagen content of the anastomosis when using the adhesion barrier polyvinyl alcohol around colonic anastomoses. The barrier did not prevent adhesion formation.
\end{abstract}

$\mathrm{T}$ HE FORMATION OF FIBROUS ADHESIONS almost always follows abdominal surgery $[1,2]$ and is a significant cause of morbidity [3-5]. Adhesions are a physiologic response to surgical trauma or infection that are the most common cause of small-bowel obstruction and female infertility and may lead to major difficulties during subsequent operative procedures [6-10]. The underlying mechanism is local tissue ischemia and mesothelial injury produced by surgical intervention, which disrupts the balance between coagulation and fibrinolysis, causing fibrous bands that result in adhesions [11]. Inflammation intensifies adhesion formation by attracting and activating fibroblasts and disrupting fibrinolysis $[12,13]$.

Numerous products have been tested to minimize the formation of adhesions, based on barriers that separate the injured surfaces long enough to allow repair without adhesions. A new adhesion barrier consisting of polyvinyl alcohol (PVA) and carboxymethylcellulose (CMC) gel (A-Part Gel ${ }^{\circledR}$;
Aesculap AG, B. Braun, Tuttlingen, Germany) has shown promising results in in vitro as well as in vivo studies [14-16]. However, in past years, several anti-adhesive agents have not entered widespread clinical use because of concerns about their interference with anastomotic site healing $[17,18]$. The primary aim of this study was to investigate the effect of the adhesion barrier PVA on the healing of colonic anastomoses using a rat model.

\section{Materials and Methods}

\section{Animals}

Thirty-two male Wistar rats (Harlan Laboratory, Horst, The Netherlands), weighing approximately $400 \mathrm{~g}$ each were divided randomly into two groups of 16: the control group and the study group that received PVA gel. The study was approved by the local ethical committee on animal welfare in accordance with animal protection laws. Animals were kept

Departments of ${ }^{1}$ Surgery, ${ }^{2}$ Neuroscience, and ${ }^{3}$ Orthopaedics, Erasmus MC, University Medical Centre, Rotterdam, The Netherlands. 
under standard laboratory conditions with individually ventilated cages and fed chow and water ad libitum throughout the study.

\section{Polyvinyl alcohol gel}

Polyvinyl alcohol gel (A-Part Gel ${ }^{\circledR}$ ) consists of PVA and $\mathrm{CMC}$. The PVA is the anti-adhesion component, whereas the CMC prevents the gel from slipping away from the operative site. The gel acts as a barrier and is applied at the end of the operation. Polyvinyl alcohol gel is absorbed completely in three to four weeks, and its main route of excretion is via the urine [19].

\section{Study design}

Animals were anesthetized by inhalation of an isofluraneoxygen mixture. The abdomen was shaved and cleaned with $70 \%$ alcohol. The abdominal cavity was opened through a midline incision of $4 \mathrm{~cm}$. The mesentery was cleaved $1 \mathrm{~cm}$ aborally to the cecum, without damaging the vessels, after which the colon was transected. An end-to-end anastomosis was formed with 12 interrupted monofilament nonabsorbable polyamide 10E sutures (Dafilon 8-0; B. Braun). In the study group, $2.0 \mathrm{~mL}$ of PVA gel was applied around the anastomosis; the control group did not receive any treatment. The colon was repositioned, and the abdominal incision was closed in two layers with synthetic absorbable braided sutures of polyglycolic acid (Safil 5-0, B. Braun). Post-operatively, rats were observed and weighed daily for one week.

\section{Outcome measurements after seven days}

On the seventh post-operative day, rats were re-operated on through a laparotomy. The abdomen was inspected for signs of anastomotic leakage (peritonitis with visible anastomotic dehiscence or peri-anastomotic abscesses).

The anastomotic bursting pressure (ABP) was measured in vivo with intact adhesions. A catheter was introduced into the colon $2 \mathrm{~cm}$ proximal to the anastomosis, with the tip lying intraluminally at the site of the anastomosis. Subsequently, the colon was ligated proximal of the probe and distal of the anastomosis in order to create a closed cavity. The pressure in the cavity was increased by pumping air through the probe at a constant rate of $100 \mathrm{~mL} / \mathrm{h}$. One limb of the probe was connected to a pressure transducer, measuring pressure continuously during infusion. Bursting of the colon followed by a sudden drop in pressure was considered to mark the ABP. After measurement of the ABP, animals were sacrificed.

Adhesions around the anastomosis were evaluated in two steps. First, the amount of adhesions was measured by determining the percentage of the anastomosis covered with adhesions. Then, the extent and characteristics of adhesions was scored according to the system of van der Ham et al. [20], which is presented in Table 1.

One centimeter of colon with the anastomosis in the middle was excised and evaluated histopathologically. The tissue was processed according to the method of Creemers et al. [21]. A colorimetric hydroxyproline assay was performed to determine the amount of collagen in the anastomotic tissue samples, as hydroxyproline is a collagen-specific amino acid. Samples were first treated with $6 \mathrm{~N}$ acid hydrolysis, followed by chloramine-T to oxidize hydroxyproline into pyrrol. Pyrrol
Table 1. Scoring System According to VAN DER HAM ET AL. [20]

\begin{tabular}{ll}
\hline Score & Extent and characteristics of adhesions \\
\hline 0 & No adhesions \\
$1+$ & $\begin{array}{l}\text { Minimal adhesions, mainly between anastomosis } \\
\text { and omentum }\end{array}$ \\
$2+$ & $\begin{array}{l}\text { Moderate adhesions; i.e., between omentum and } \\
\text { the anastomotic site and between the } \\
\text { anastomosis and a loop of small bowel } \\
3+\end{array}$ \\
$\begin{array}{l}\text { Severe and extensive adhesions, including } \\
\text { abscess formation }\end{array}$ \\
\hline
\end{tabular}

was converted into a chromophore (red) by dimethylaminobenzaldehyde. Using a wavelength of $570 \mathrm{~nm}$, the amount of red color reflects the amount of hydroxyproline, assuming 300 hydroxyproline residues per collagen triple helix.

\section{Statistics}

The normality of the data was determined by means of the Shapiro-Wilk test and visual assessment. Categorical data (adhesion scores) are presented as numbers with percentages, and numerical data are presented as means with standard errors of the mean (normally distributed) (SEM) or medians with interquartile ranges (not normally distributed). Differences between groups were assessed using an $\chi^{2}$ test for categorical data (adhesion scores) or an unpaired $t$-test (normally distributed) or Mann-Whitney U test (not normally distributed) for numerical data.

\section{Results}

In the control group, there were no sick or dead animals before day 7 . There was one death in the study group on day 3 secondary to dehiscence of the laparotomy. Necropsy showed no intra-abdominal pathology. As can be seen in Figure 1, there was no significant difference in weight loss in the two groups.

At the time of reoperation on day 7, no signs of anastomotic leakage were seen. There were no visual remnants of PVA gel intra-abdominally. The mean result of the ABP measurements

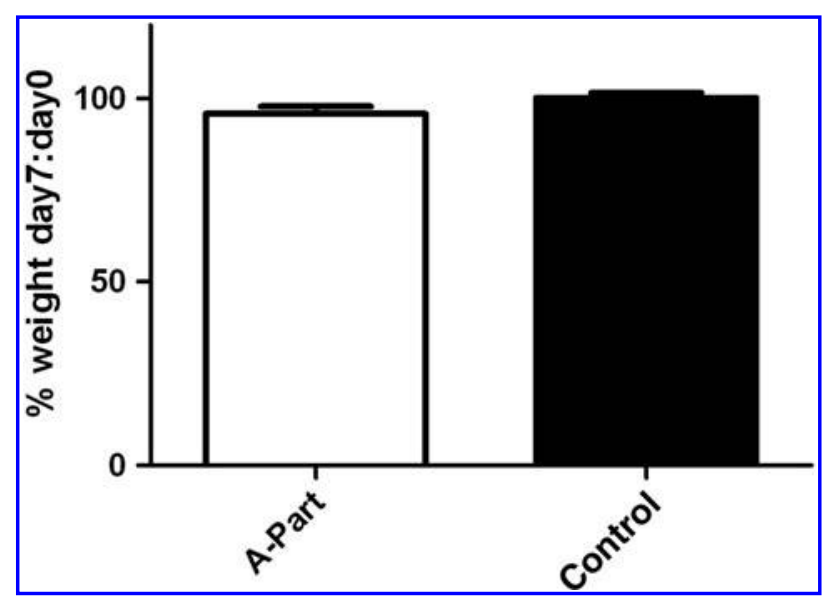

FIG. 1. Percentage of weight on day 7 compared to day 0 (mean with SEM). 


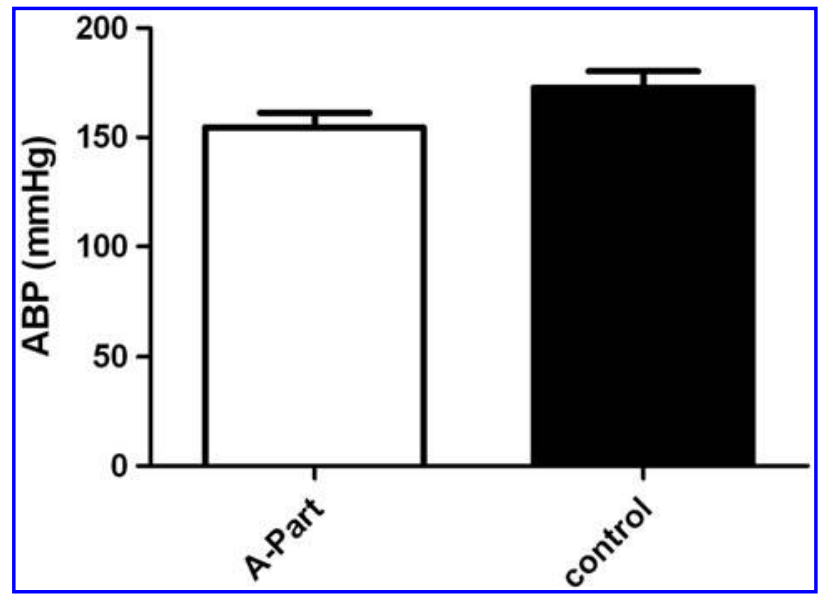

FIG. 2. Anastomic of bursting pressure (mm Hg) (mean with SEM).

can be seen in Figure 2: $155.0 \pm 6.7 \mathrm{~mm} \mathrm{Hg}$ in the PVA group and $173.0 \pm 7.5 \mathrm{~mm} \mathrm{Hg}$ in the control group. This difference was not statistically significant $(p=0.08)$. All burstings were at the anastomosis. The median circumference of the anastomosis covered with adhesions was $90 \%$ (range $70 \%-100 \%$ ) in the PVA group, and $80 \%(70 \%-83.8 \%)$ in the control group (Fig. 3). This difference was not statistically significant $(p=0.30)$. The results of the extent and characteristics of the adhesions covering the anastomosis can be found in Table 2. Adhesion scores in the PVA and the control group were not statistically different $(p=0.39)$. The median quantity of collagen per $\mathrm{mg}$ of dry weight was $7.9 \mathrm{mcg}$ (range 6.8-12.9 mcg) in the PVA group and $8.9 \mathrm{mcg}$ (6.7-9.4 mcg) in the control group (Fig. 4). This difference was not statistically significant $(p=0.91)$.

\section{Discussion}

Adhesions are fibrous bands that form between two damaged peritoneal surfaces that normally are separated. In 1973, Raftery showed that injury of the serosal layer of the peritoneum leads to an inflammatory exudate followed by fibrin deposition, which is the beginning of adhesion formation [22]. The precise underlying mechanism is com-

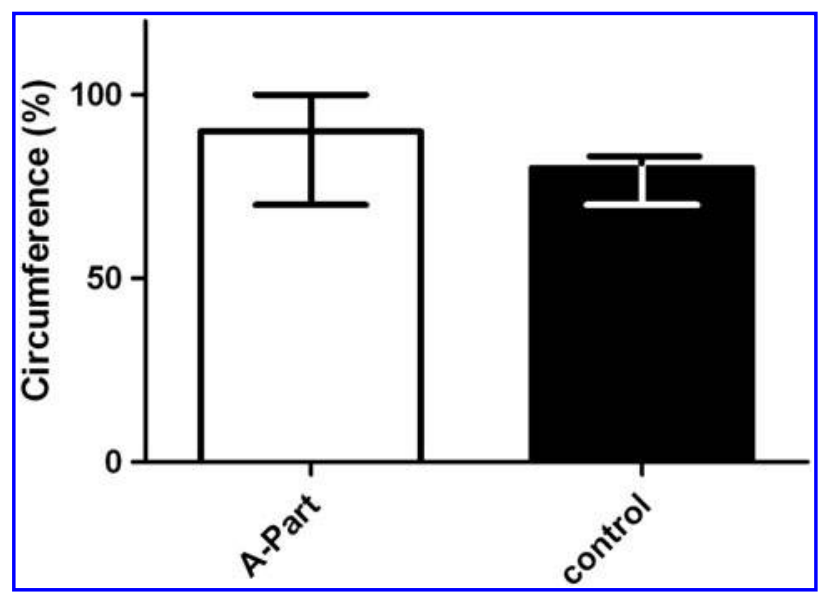

FIG. 3. Circumference of the anastomosis covered with adhesions (\%) (median with interquartile range).
TAble 2. Adhesions Scores

\begin{tabular}{lccc}
\hline $\begin{array}{l}\text { Adhesions } \\
\text { score }\end{array}$ & $\begin{array}{c}\text { Treated } \\
(n=15)(\%)\end{array}$ & $\begin{array}{c}\text { Control } \\
(n=16)(\%)\end{array}$ & $\begin{array}{c}P \\
\text { value }\end{array}$ \\
\hline 0 & 0 & 0 & \\
1 & $3(20)$ & $1(6.3)$ & \\
2 & $9(60)$ & $13(81.3)$ & \\
3 & $3(20)$ & $2(12.5)$ & 0.39 \\
\hline
\end{tabular}

plex: The clotting pathway, extracellular matrix proteins, and various cytokines and growth factors are involved [2325] with eventual production of a fibrin matrix with fibroblasts and collagen that creates the adhesions. Fibrinolytic activity resolves this fibrin matrix $[26,27]$ and is necessary for a balance between the formation and breaking down of fibrous deposits. However, fibrinolysis is reduced by inflammation and infection, and thus the balance is disturbed after surgery, particularly when surgery is followed by an infectious complication.

Adhesions are a frequent problem after abdominal surgery, with an incidence as high as $95 \%$, resulting in important and invalidating complications such as bowel obstruction, female infertility, and chronic pain [6-8,10,22,23]. In addition to their undesirable clinical impact, adhesions are associated with substantial increases in health cost, as has been shown by large trials on adhesion-related readmissions conducted by Ellis et al. [3] and Parker et al. [4]. Therefore, adhesion prevention would be a highly valuable extension of surgical interventions, as surgical trauma is one of the most important triggers of the formation of adhesions.

Several ways of adhesion prevention have been studied, the majority involving intra-abdominally applied adhesion barriers with the goal of separation of the damaged peritoneal surfaces. The adhesion barrier used in this gastrointestinal study, PVA, is used in many other medical specialties [28-30] and has a solubility, biocompatibility, and inactivation in body fluids properties that makes it a suitable adhesion barrier [31]. PVA diminishes adhesions in vitro, after spinal surgery, and after tendon surgery [31-33]. To improve quality of adherence of the barrier to the viscera, CMC was added to PVA gel. Jaenigen et al. [14] showed in a rabbit sidewall model

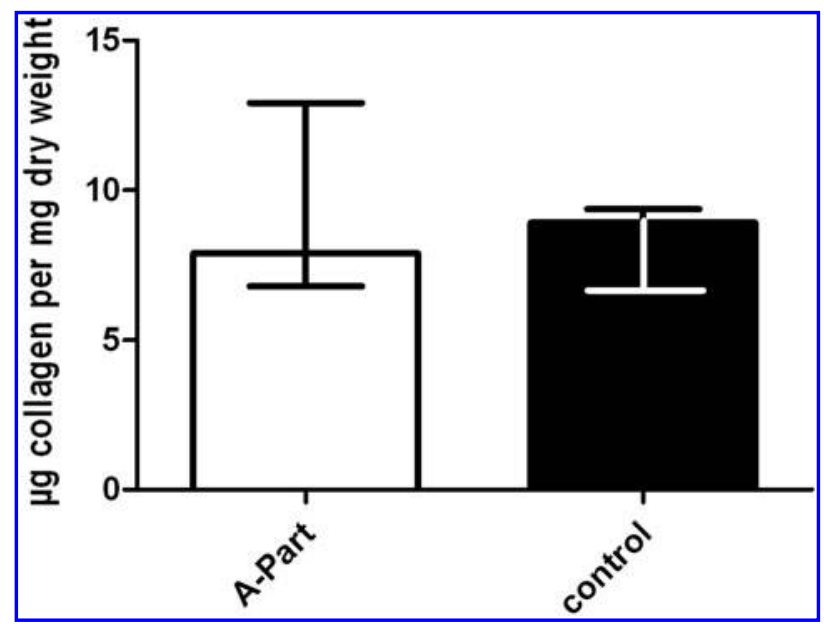

FIG. 4. Collagen ( $\mu$ g collagen per mg dry weight) (median with interquartile range). 
that this PVA-CMC gel diminishes adhesions compared with untreated controls and animals given $4 \%$ icodextrin. Lang et al. [15] found similar results in their rabbit sidewall model; significantly fewer adhesions were present in rabbits treated with PVA-CMC gel than in those given $4 \%$ icodextrin and in controls. Good results also were obtained in their re-laparotomy model [16].

However, if an adhesion barrier is capable of diminishing fibrin deposition to a sufficient extent to prevent adhesions, it is essential to show that healing, which also relies on fibrin deposition followed by collagen formation, is not impaired. The consequence of impaired healing of a gastrointestinal anastomosis is leakage, leading to abscesses or peritonitis with a mortality rate between $10 \%$ and $20 \%$. This lifethreatening complication makes the balance between diminishing adhesions and encouraging incision healing crucial in gastrointestinal surgery. Previous studies have emphasized this fragile balance through results showing more anastomotic leakage in patients receiving a hyaluronic acid (HA) and CMC anti-adhesive film. Initial results with this film were promising, with an impressive reduction of $50 \%$ in the number of adhesions to the midline incision. Following these results, a randomized safety study was performed by Beck et al. [17] with 1,791 patients undergoing abdominopelvic surgery. This study showed there were significantly more abscesses, anastomotic leakages, and peritonitis cases in the patients with the HA-CMC film. Subgroup analysis of all patients with anastomoses showed the placement of HA-CMC film directly on the anastomosis increased the risk of anastomotic leakage compared with control subjects, whereas there was not a problem when the HA-CMC film was not placed on the anastomosis. An experimental study with the same anti-adhesive film showed that wrapping it around an irradiated bowel anastomosis in rats resulted in significantly more peri-anastomotic abscesses than were seen in non-treated controls [18]. Such results stress the importance of testing adhesion barriers in situations where impairment of healing has severe and potentially life-threatening consequences.

The aim of this study was to investigate the effect of PVACMC gel (A-Part Gel ${ }^{\circledR}$ ) on healing and strength of colonic anastomoses in a rat model. The model, with a 12-suture anastomosis in the colon, represents normal healing of an anastomosis without leakage. No difference in weight loss was observed in rats with and without PVA gel, nor were there any signs of anastomotic leakage in either group. No significant differences in ABP were observed. One dead animal was found at day 3 . The death probably was not related to the A-Part Gel, as there was dehiscence of the laparotomy, and the stitch was bitten through. Measurements of collagen showed no significant differences between PVA rats and controls after seven days, indicating this adhesion barrier does not interact with collagen synthesis during wound healing. The seventh post-operative day was chosen for collagen measurement and $\mathrm{ABP}$, as collagen synthesis is greatest between the fifth and the seventh post-operative days, and anastomotic strength depends mainly on newly formed collagen [34].

This study has several weaknesses. Pre-study power analysis showed 16 animals per group to be sufficient; however, a power analysis always implies some theoretical supposition. With a $\mathrm{p}$ value of 0.08 , a trend toward more anastomotic leakage in the study group cannot be excluded completely. Therefore, more research with A-Part Gel® and intestinal anastomoses is necessary. Also, the effect of the coverage of the anastomoses with adhesions is not certain. In our rodent model, we practically always see a large area of coverage of the anastomosis by adhesions on day 7 , with the adhesions coming mainly from omentum attached to suture material and anastomotic edges, without anastomotic leakage. Adhesion formation in this setting may be secondary to a foreignbody reaction to suture material, which differs from the response seen to bacterial soiling or blood clot. Lauder et al. [35] and Silva et al. [36] have observed similar results: Persistence of adhesions to the anastomosis in both the control group and the adhesion-barrier group. In this study, we saw coverage of the anastomosis with adhesions in both groups; therefore, whether there is an influence of these adhesions on anastomotic leakage cannot be known. In our model, no reduction of adhesions was found. However, the effect of PVA gel on adhesions has been described in several studies using the sidewall model, with excellent results as defined by adhesion reduction.

In conclusion, this randomized study in rats showed no significant differences in anastomotic leakage, anastomotic bursting pressure, or collagen content of the anastomosis when the adhesion barrier PVA gel was delivered around colonic anastomoses. There appeared to be no effect on adhesion formation.

\section{Acknowledgments and Author Disclosure Statement}

This study was supported by Aesculap AG, B. Braun, Tuttlingen, Germany. The authors have no other conflicts of interest to declare.

\section{References}

1. Operative Laparoscopy Study Group. Postoperative adhesion development after operative laparoscopy: Evaluation at early second-look procedures. Fertil Steril 1991;55:700704.

2. Becker JM, Dayton MT, Fazio VW, et al. Prevention of postoperative abdominal adhesions by a sodium hyaluronatebased bioresorbable membrane: A prospective, randomized, double-blind multicenter study. J Am Coll Surg 1996;183:297306.

3. Ellis H, Moran BJ, Thompson JN, et al. Adhesion-related hospital readmissions after abdominal and pelvic surgery: A retrospective cohort study. Lancet 1999;353:1476-1480.

4. Parker MC, Ellis H, Moran BJ, et al. Postoperative adhesions: Ten-year follow-up of 12,584 patients undergoing lower abdominal surgery. Dis Colon Rectum 2001;44:822-829.

5. Wilson MS, Ellis H, Menzies D, et al. A review of the management of small bowel obstruction. Members of the Surgical and Clinical Adhesions Research Study (SCAR). Ann R Coll Surg Engl 1999;81:320-328.

6. McEntee G, Pender D, Mulvin D, et al. Current spectrum of intestinal obstruction. Br J Surg.1987;74:976-890.

7. Menzies D, Ellis H. Intestinal obstruction from adhesionsHow big is the problem? Ann R Coll Surg Engl 1990;72: 60-63.

8. Milingos S, Kallipolitis G, Loutradis D, et al. Adhesions: Laparoscopic surgery versus laparotomy. Ann N Y Acad Sci 2000;900:272-285. 
9. Stewart RM, Page $\mathrm{CP}$, Brender J, et al. The incidence and risk of early postoperative small bowel obstruction: A cohort study. Am J Surg 1987;154:643-647.

10. van der Krabben AA, Dijkstra FR, Nieuwenhuijzen M, et al. Morbidity and mortality of inadvertent enterotomy during adhesiotomy. Br J Surg 2000;87:467-471.

11. Reijnen MM, Bleichrodt RP, van Goor H. Pathophysiology of intra-abdominal adhesion and abscess formation, and the effect of hyaluronan. Br J Surg 2003;90:533-541.

12. Cahill RA, Wang JH, Soohkai S, Redmond HP. Mast cells facilitate local VEGF release as an early event in the pathogenesis of postoperative peritoneal adhesions. Surgery 2006;140:108-112.

13. Liebman SM, Langer JC, Marshall JS, Collins SM. Role of mast cells in peritoneal adhesion formation. Am J Surg 1993;165:127-130.

14. Jaenigen BM, Weis C, Odermatt EK, et al. The new adhesion prophylaxis membrane A-From in vitro testing to first in vivo results. J Biomed Mater Res B Appl Biomater 2009;89B: 293-299.

15. Lang RA, Gruntzig PM, Weisgerber C, et al. Polyvinyl alcohol gel prevents abdominal adhesion formation in a rabbit model. Fertil Steril 2007;88(4 Suppl):1180-1186.

16. Lang RA, Weisgerber C, Gruntzig PM, et al. Polyvinyl alcohol gel prevents adhesion re-formation after adhesiolysis in a rabbit model. J Surg Res 2009;153:12-16.

17. Beck DE, Cohen Z, Fleshman JW, et al. A prospective, randomized, multicenter, controlled study of the safety of Seprafilm adhesion barrier in abdominopelvic surgery of the intestine. Dis Colon Rectum 2003;46:1310-1319.

18. Bowers D, Raybon RB, Wheeless CR Jr. Hyaluronic acidcarboxymethylcellulose film and perianastomotic adhesions in previously irradiated rats. Am J Obstet Gynecol 1999; 181:1335-1337.

19. Besheer A, Mader K, Kaiser S, et al. Tracking the urinary excretion of high molar mass poly(vinyl alcohol). J Biomed Mater Res B Appl Biomater 2007;82:383-389.

20. van der Ham AC, Kort WJ, Weijma IM, et al. Effect of fibrin sealant on the healing colonic anastomosis in the rat. $\underline{\mathrm{Br} \mathrm{J}}$ Surg 1991;78:49-53.

21. Creemers LB, Jansen DC, van Veen-Reurings A, et al. Microassay for the assessment of low levels of hydroxyproline. Biotechniques 1997;22:656-658.

22. Raftery AT. Regeneration of parietal and visceral peritoneum: An electron microscopical study. J Anat 1973;115(Pt 3): 375-392.

23. McBride WH, Mason $K$, Withers HR, Davis C. Effect of interleukin 1, inflammation, and surgery on the incidence of adhesion formation and death after abdominal irradiation in mice. Cancer Res 1989;49:169-173.
24. Milligan DW, Raftery AT. Observations on the pathogenesis of peritoneal adhesions: A light and electron microscopical study. Br J Surg 1974;61:274-280.

25. Ryan GB, Grobety J, Majno G. Mesothelial injury and recovery. Am J Pathol 1973;71:93-112.

26. Raftery AT. Regeneration of peritoneum: A fibrinolytic study. J Anat 1979;129(Pt 3):659-664.

27. Thompson JN, Whawell SA. Pathogenesis and prevention of adhesion formation. Br J Surg 1995;82:3-5.

28. Li F, Su Y, Wang J, et al. Influence of dynamic load on friction behavior of human articular cartilage, stainless steel and polyvinyl alcohol hydrogel as artificial cartilage. I Mater Sci Mater Med 2010;21:147-154.

29. Mohammadi H, Boughner D, Millon LE, Wan WK. Design and simulation of a poly(vinyl alcohol)-bacterial cellulose nanocomposite mechanical aortic heart valve prosthesis. Proc Inst Mech Eng H 2009;223:697-711.

30. Abramowitz SD, Israel GM, McCarthy SM, et al. Comparison of four embolic materials at uterine artery embolization by using postprocedural MR imaging enhancement. Radiology 2009;250:482-487.

31. Weis C, Odermatt EK, Kressler J, et al. Poly(vinyl alcohol) membranes for adhesion prevention. J Biomed Mater Res B Appl Biomater 2004;70:191-202.

32. Hiraizumi Y, Transfeldt EE, Fujimaki E, Nambu M. Application of polyvinyl alcohol hydrogel membrane as antiadhesive interposition after spinal surgery. Spine 1995;20: 2272-2277.

33. Kobayashi M, Toguchida J, Oka M. Development of the shields for tendon injury repair using polyvinyl alcoholhydrogel (PVA-H). J Biomed Mater Res 2001;58:344-351.

34. Jiborn H, Ahonen J, Zederfeldt B. Healing of experimental colonic anastomoses III: Collagen metabolism in the colon after left colon resection. Am J Surg 1980;139:398-405.

35. Lauder CI, Garcea G, Strickland A, Maddern GJ. Use of a modified chitosan-dextran gel to prevent peritoneal adhesions in a rat model. I Surg Res 2011;171:877-882.

36. Silva SM, Ferreira VM, Feres O, et al. Does metoclopramide impair anastomotic healing of the left colon of rats? Acta Cir Bras 2011;26:297-302.

Address correspondence to: Dr. Juliette C. Slieker Room Ee-173: Laboratory of Experimental Surgery Erasmus MC Postbus 2040 3000 CA Rotterdam, The Netherlands E-mail: juliette_slieker@hotmail.com 